\title{
XXXVII Congreso de Químicos Teóricos de Expresión Latina, Quitel 2011
}

\author{
Gabriel Merino • Alberto Vela • Alejandro Toro-Labbe
}

Published online: 6 April 2013

(C) Springer-Verlag Berlin Heidelberg 2013

The XXXVII Congress of Theoretical Chemists of Latin Expression (Quitel 2011) was held in Riviera Maya (Mexico) from 4-9 December 2009. About 250 participants from 25 countries gathered for 5 days of lectures, poster sessions, and informal discussion. The Congress took place at the Barcelo Mayan Palace, set on the Riviera Maya, overlooking the Caribbean Sea. The atmosphere was highly stimulating and promoted many rich and fruitful discussions among the participants, contributing to strengthening previous collaborations and to start new among the community of theoretical chemists with common Latin origins.

The program consisted of 12 plenary lectures, 51 short oral communications, and two poster sessions. These proceedings contain papers from many of the Congress sessions and are a representative sample of the high scientific level that we had in the Quitel. All contributions followed the normal editorial process of manuscripts submitted to the Journal of Molecular Modeling.

The organizers are pleased to acknowledge the support given to the Quitel 2011 by Universidad de Guanajuato, Cinvestav, Cimav, Universidad NacionalAutónoma de Mexico, Universidad AutónomaMetropolitana, Benemérita Universidad Autónoma de Puebla, Universidad del País Vasco, Lufac, and Scientific Computing\& Modeling, and Academia de Catálisis. The contributions of our sponsors enabled us to maintain the high-quality standard of this Quitel meeting.

We are grateful to all participants for making this Congress a stimulating and unforgettable experience.

G. Merino $(\bowtie)$

Departamento de Física Aplicada, Centro de Investigación y de Estudios Avanzados, 97310, Mérida, Yucatán, Mexico

e-mail: gmerino@mda.cinvestav.mx

\section{A. Vela}

Departamento de Química, Centro de Investigación y de Estudios Avanzados, Av. IPN 2508, Colonia San Pedro Zacatenco 07360, Mexico, D.F. 07360, Mexico

\section{A. Toro-Labbe}

Laboratorio de Química Teórica Computacional (QTC),

Facultad de Química, Pontificia Universidad Católica de Chile, Casilla 306, Correo 22,

Santiago, Chile 